\title{
Refranes para la gente culta
}

\author{
J osé Carlos \\ Escobar Hernández \\ ESELA-UNAM
}

\section{INTRODUCCIÓN}

¡Quétítulo más desconcertante y atractivo el de esta nota!

$Y$ es que, generalmente, se define al refrán como un dicho "tradicional", al go que, por pura mala suerte, se ha convertido en un término opuesto a "culto", no obstante se haya dicho que contiene:

a) una "advertencia", como las que suelen dar quienes ocupan un lugar reconocido como autoridad,

b) una "enseñanza", como si tuviera la capacidad propia de un erudito o los conocimientos de un educador,

c) o bien un "consejo", como el que suelen dar quienes han logrado la sabiduría.

Resulta, igual mente desconcertante, nuestra tendencia adicional a relacionar lo "tradicional "con lo "típico" y lo "popular", siendo que "culto" —un término igualmente tradicional, y cada día más popular conforme nuestro puebl o se instruye - es por su parte sinónimo de "ilustrado" y "sabio", ique coincidencia!

Pero bueno, como sea y muy a pesar de lo que la Academia o las etiquetas forzadas dicten, al final la influencia de los refranes es tan pedestre que, lo mismo que el aguardiente pueden y suelen ser capaces de embriagar igual tanto a un embajador que al mismísimo presidente, aunque a pesar de ser del dominio de una comunidad lingüística asociada con todo lo que ha si do catal ogado como "inculto". En el mundo académi co, los refranes no suel en ser asociados con el concepto de lo "cul to" en general, quizá por un respeto a al guna tradición paral ela: porque admiramos y respetamos mucho más todo lo que nos viene de fuera y no resulta 
ajeno, por más que los de la alta alcurnia hayan acordado -muy benévolamente — concederle el titulo de "sabiduría popular".

Por principio, nadie se ha preocupado por cultivar o cultivarse en el manejo de los dichos y los refranes y tal vez por eso se encuentran en peligro de extensión. Como vemos, resulta innegable que, aun cuando sólo sea por una mera costumbre irreflexiva, la pal abra "refranes" choca con la palabra "culta", pero hay que recorder que esto no sucede cuando los usamos en casa, con nuestros amigos o en nuestras relaciones más cercanas, sino únicamente cuando tomamos conciencia de que lo hacemos por la etiqueta que hemos endilgado a estos vocablos, resultado histórico no sólo de la Conquista - que ya muy desgastada está, aunque no del todo-, sino de nuestra sempiterna capacidad humana y gusto por etiquetar, diferenciar y precisar cuanto se nos pone enfrente, si bien paradójicamente el lenguaje mismo nos ha capturado en su propia manera de ver las cosas.

Si bien el lenguaje nos hizo evolucionar hacia la clase de los sapiens sapiens se nos ol vi da que constantemente debemos enfrentarnos a la trampa que nuestro propio lenguaje impone a nuestra mente cuando define y fija de una manera limitada nuestraconcepción general del mundo, o mejor dicho, del mundo general que nos rodea.

\section{LA DIFERENCIA ENTRE CULTO Y COLOQUIAL}

La diferencia entre lo culto y lo col oquial es la misma que la diferencia entre el mundo real y el mundo ideal, entre lo natural y lo artificial, entre lo pedestre y lo sublime. Por un lado, en realidad no hay nada más literal y poco evocador que el lenguaje científico y técnico, muy simiIar al lenguaje culto cuando aparece recargado de palabras de hechura etimológica muy diversa, cuando no se ha tenido la oportunidad de ver en sus componentes los residuos de las imágenes pasadas que les dieron origen. Ambos lenguajes miran el mundo con la sangre fría del cerebro izquierdo -lógico y calculador, amante de la verdad y de lo "objetivo", cuando apenas alcanza el nivel 
intersubjetivo-, pretendiendo huir siempre de la mera evocación o sugerencia, propia del cerebro derecho -que es sensible, estético, fugaz e inefable.

De los mundos de la nominalización (forjada básicamente por los sustantivos) y dela predicación (forjada por los enunciados como una totalidad más amplia) resulta muy interesante ver la natural eza de los lenguajes coloquial (hecho con base en enunciados) y culto (confeccionado con sustantivos, adjetivos y verbos muy precisos). No es lo mismo expresarse con frases precisas que responden a la función nominativa del lenguaje que con frases evocativas o unidades fraseológicas que ponen delante de nosotros una realidad y la explican de una manera más cercana a la propia real idad sociocultural de un pueblo, siendo ésta la principal función del uso figurado y metafórico del lenguaje (por cierto comprensible gracias al hemisferio derecho de nuestro cerebro).

\section{EL MUNDO REAL}

Los dichos son reflejo de una real idad y una cultura. Se ha afirmado, y muy bien, que los dichos y los refranes reflejan las vivencias y el conocimiento práctico de los pueblos. El español es abundante en experiencias fiel mente concretadas en sus dichos y sus refranes, que además describen muchos aspectos sociol ingüísticos de nuestro idioma. Recordemos que la mayoría de los refranes se expresan parcial mente por razones de un estilo sugerente o porque se da por sentado que todos los hablantes conocen tanto el contenido como su intención o efecto.

J unto con los dichos, este tipo de enunciación produce el efecto de un cierto interés sobre lo referido. Pero lo más importante: reflejan una realidad y una cultura determinadas que nos Il ega desde el pasado y probablemente se proyecta hacia el futuro. Esto se puede comprobar fácilmente si se los clasifica de diferentes maneras, agrupados en los siguientes tipos. 
Dichos contradictorios

Al que madruga, Dios lo ayuda. El que es persistente y trabajador obtiene siempre buenos resultados. Quien se levanta temprano tiene tiempo para hacer muchas otras cosas más, antes que otros y con ventaja sobre ellos.

No por mucho madrugar, amanece más temprano. De aquí se entiende que cada cosa debe hacerse a su tiempo, una a una, pues aunque tarden en Ilegar, finalmente se consiguen si así tiene que ser.

El que tiene más saliva, traga más pinole. En una discusión siempre gana el que sabe hablar mejor o es más hábil para hacerlo. Se alude a la dificultad de comer el pinole, que es un polvo semejanteal chocolate que se espesa con nuestra sal iva al tratar de comerlo. Así, "tener más saliva" es "tener una mayor capacidad de hablar" o "tener las palabras para decir las cosas".

No se puede chiflar y comer pinole. No es posible hacer al mismo tiempo dos tareas cuando son incompatibles (véase: "El que tiene más sal iva come más pinole").

Con estos dichos, ¿quién nos va a entender?

Dichos que proponen normas de vida

A fortunado en el juego, desafortundado en el amor. Se considera que en esta vida tenerlo todo es imposible.

Al mal paso, darle prisa. Si uno ha deenfrentarseauna empresa difícil o desagradable, hay que hacerlo de una vez.

Amor de lejos, es de pen... sarse bien. El amor crece con la cercanía y los detalles cotidianos. Lo contrario es como "hacerse tonto".

Cae más pronto un hablador, que un cojo. Con esta frase se indica que las mentiras se descubren muy pronto.

Candil de la calle, oscuridad de su casa. Se dice de las personas que atienden los asuntos de otros antes que los suyos propios.

De limpiosy tragones, están Ilenos los panteones. Con esta frase tratan de disculparse los que piensan que no es necesario ser total mente honrados en esta vida. Por supuesto, los cuidados excesivos no evitan la muerte. 
El flojo trabaja doble. Se dice quesi la persona es floja y no hace bien las cosas, acabará por hacerlas una segunda vez cuando así se le requiera.

El que a hierro mata, a hierro muere. Se considera muy alta la posi bilidad de quesi al guien mata a otro, puede morir a manos de al guien más.

El que come y canta, loco se levanta. El hecho de cantar sin motivo y de tener buen apetito, son las mejores muestras de que la persona está « oca»por la vida (es decir, muy feliz), pues ignora todas las cosas negativas.

El que la hace, la paga. Así se sugiere que somos responsables de nuestros actos.

El que mucho abarca, poco aprieta. La dispersión en las actividades ocasiona que todas se hagan mal, a medias o de manera incompleta. Es mejor concentrarse en una sola actividad y hacerla bien.

El que no oyeconsejo, no llega a viejo. Esaconsejable escuchar los consejos de quienes tienen la experiencia.

El que por su gusto muere, hasta la muerte le sabe. Hacer al go que nos perjudica, con toda conciencia y aceptando las consecuencias. El que hace así obra, no tiene derecho a quejarse.

El que ríe al último, ríe mejor. Es la idea que alienta a quienes son constantemente humillados por quienes se creen mejores. Siempre existe la posibilidad de demostrar lo contrario.

El que sabe, sabe. No podemos dudar de quien es realmente experto.

El que se enoja, pierde. Advertencia para que, en caso de un conflicto, no perdamos a causa de nuestro enojo o descontrol.

El que sefuea la villa, perdió su silla. Frase para indicar que el quese descuida puede perder sus bienes o su posición privilegiada. La «villa»de Guadalupe es el lugar de peregrinación para los mexicanos.

El que trabaja a lo honrado, se vuel ve jorobado. LOS años de trabajo duro y el paso del tiempo vuelven jorobadas a las personas. Alude a lo pesado y difícil que resulta vivir de un trabajo honrado, en un mundo que no lo es.

El valiente vive hasta que el cobarde quiere. Hay que tener cuidado con quienes se dejan abusar, pues un buen día se cansan y pueden buscar venganza. 
Habrá quien tequiera, pero quien te ruegue, nunca. Es posible que al guien te quiera, pero si tú no vas a hacer al go, nadie te va a estar rogando que lo hagas (no eres tan importante como piensas).

Haz el bien sin mirar a quién. Si vamos a hacer algo bueno por al guien, no debemos detenernos a considerar primero de quién se trata o si se lo merece.

Hay que beberla o derramarla. Se dice de la exigencia, responsabilidad o empresa que debe cumplirse a como dé lugar.

La ociosidad es la madre de todos los vicios. Se piensa que una persona, al no tener actividad constructiva alguna, se dedicará a pensar en cosas malas.

La suerte de la fea, la bonita la desea. Se dice que las mujeres feas suelen conseguir al hombre más bueno, guapo o inteligente.

La unión hace la fuerza. Consideramosquetodos, unidos, podemos ser más fuertes y vencer la adversidad, pues la colaboración sirve de mucho en cualquier empresa.

La verdad no peca, pero incomoda. A nadie le gusta que le digan sus verdades (defectos) o que le hagan ver sus errores, pues ello causa vergüenza.

Mal de muchos, consuelo de tontos. No debemos conformarnos con la adversidad sólo porque muchos padecen de nuestros mismos males.

Más pronto cae un hablador, que un cojo. Se dice esto para las personas que dicen no querer hacer algo y sin embargo, lo hacen a la primera oportunidad.

Más sabe el diablo por viejo, que por diablo. Con esta idea se alude a la importancia que adquieren las personas por la experiencia que han tenido, más que por cualquier otra especialización.

Más vale paso que dure, y no trote que canse. Cuando las cosas se tienen que hacer hay que hacerlas, aunque sea despacio pero bien y no rápido y mal.

Más vale prevenir que lamentar. Es mejor pensar las cosas antes que hacerlas precipitadamente y sin saber cuáles pueden ser sus consecuencias negativas.

Más vale solo que mal acompañado. Con esto expresamos que si al guien no es una buena influencia, es mejor estar a solas. 
Más vale una horatarde, que un minuto desilencio. Esmucho mejor llegar tarde que correr imprudentemente corriendo el riesgo de morir a causa de un accidente.

Músico pagado, toca mal son. No es prudente pagar por adelantado los trabajos que se encomiendan.

Ni muy muy, ni tan tan. Frase que sugiere no llegar a los extremos y tratar de conservar el equilibrio de las cosas. Por ejemplo, se queremos tomar algo, probablemente quisiéramos que no esté "ni muy (frío), ni tan (caliente)".

No hay mal que, por bien, no venga. Se considera que, aun cuando los males nos afectan, siempre podemos aprovechar esa situación o experiencia para aprender y sacar de ella al go bueno.

No hay plazo que no se cumpla. La sentencia indica que todo tiene su fin (la vida, el trabajo, y cualquier plazo en general).

No soy monedita de oro, pa' caerle bien a todos. Con esta frase trata de discul parse el que, sabiendo que no es nadie especial ni diferente a los demás, corre el riesgo de no ser agradable a todos.

Querer es poder. Podemos conseguir las cosas si verdaderamente las deseamos.

Quien mal anda, mal acaba. Lo que empieza bien, termina bien. Así esta sentencia sugiere lo contrario.

Quien persevera alcanza. Si emprendemos una tarea o empresa, debemos seguir hasta lograr nuestros obejtivos (Io mismo que Querer es poder).

Si quieres quealguien se ría, cuenta tus penas María. Con esto se sugiere guardar discreción en lo relacionado con nuestros problemas personales, pues no competen a nadie sino a nosotros mismos.

Una mala noche como quiera se pasa. Así se expresa quien encuentra un lugar para pasar la noche, aunque sea incómodamente.

Vale más aquí corrió, que aquí quedó. Esto es una recomendación a rehuir una pel ea que puede acabar en tragedia (sedice “aquí quedó" al que caemuerto en un lugar).

Quien no oye consejos, no llega a viejo, dicen por ahí. 
Dichos sobre costumbres mezquinas

¿A quién le dan pan quellore? Todo lo gratuito siempre es bien recibido, aunque sea ilegal .

El que no tranza, no avanza. Así piensan los que son corruptos y abusivos ("tranzar" es defraudar).

En arca abierta, hasta el más justo peca. ¿Quién al ver un tesoro abandonado no lo tomaría? El refrán afirma que, de haber una oportunidad, todos podemos vernos tentados a aprovecharnos de las cosas.

Díme cuánto tienes y te di ré cuánto vales. Se considera que la riqueza hace mejores a los individuos (de ahí que las apariencias y la imagen de la persona sea muy importante, aunque no hay que olvidar los buenos sentimientos y valores).

El que parte y reparte, se queda con la mayor parte. El encargado de administrar tiene la posibilidad de ser el más beneficiado, pues una vez que ha dado a otros su parte, puede disponer del resto.

Otros como estos son:

De que lloren en su casa, a que lloren en la mía, mejor quelloren en la suya. Ni modo. y Que tanto estantito, que han demostrado ser bastante funestos en la conformacion de nuestra sociedad.

\section{Dichos con referencias a la ropa}

A fuerza, ni los zapatos entran. No es posible obligar a una persona a hacer lo que no desea.

A quien le venga el saco, que se lo ponga. Se dice cuando lo afirmado por al guien puedealudir directamente a otra persona. (A cual quiera de los presentes).

Aunque la mona se vista de seda, mona se queda. Hay personas que, por más que traten, no pueden cambiar o negar lo que ya son. También se dice: Pelado que se ha encumbrado, no deja de ser pelado (no importa el progreso económico de la persona si no cambia sus modales y manera de vivir. 
Nunca falta un roto para un descosido. Con esto se asegura que, si la gente piensa que tiene mala suerte y que sólo a ella le suceden cosas trágicas o desagradables, no está aislada, pues hay muchos que sienten o sufren lo mismo.

Como te ven te tratan, dice la sabiduría popular.

Dichos de contenido doméstico

Al hablar, como al guisar, su granito de sal. Hay que tratar de darle "sabor" (sal/ chispa) a lo que decimos, para enriquecerlo.

Almuerza bien, come más, cena poco y vivirás. este refrán nos enseña cómo administrar nuestros diarios al imentos.

A todo se acostumbra uno, menos a no comer. Así se sugiere que es posible aguantar (resistir) cualquier cosa, excepto el hambre.

Barriga llena, corazón contento. Una vez que hemos comido, nos sentimos a gusto y somos más felices. Se dice para cel ebrar que hemos tenido el sustento del día.

El que nace pa' maceta, del corredor no pasa. Expresa el hecho de que al gunas personas nunca logran su propio progreso o que su destino no puede ser cambiado.

Lo que se ha de pelar, que se vaya remojando. Cuando tenemos que hacer algo, lo mejor es prepararnos e iniciar nuestras acciones con la mejor disposición.

Todo cabe en un jarrito, sabiéndolo acomodar. Palabras que nos recuerdan que al acomodar las cosas podemos hallarles un buen lugar para que no estorben ( por ejemplo, al hacer nuestras maletas de viaje o al distribuir los muebles de la casa que son numerosos y aparentan no tener posibilidad deocupar un espacio adecuado).

Dichos con mención de animales diversos

A perro hambriento no le importan palos. Se dice de quien, antela necesidad extrema, soporta humillaciones para poder subsistir y seguir adelante. 
Como quitarle un pelo a un gato. Se aplica al hecho de que si tomamos al go de quien tiene mucho o tiene en exceso es como si no tomáramos nada (es decir, que no les presupone ningún esfuerzo o sacrificio)

Con dinero, baila el perro. Así dicen los que en las calles dan espectáculo con sus perritos bailarines. El refrán habla del poder del dinero, que lo mueve todo (simbolizado por el perro en este refrán).

Cría cuervos, y te sacarán los ojos. El que no sabe educar a sus hijos puede esperar lo peor de ellos. También se dice de los amigos traicioneros.

Camarón que se duerme, se lo lleva la corriente. En un sól o descuido podemos perder mucho o perderlo todo.

De noche todos los gatos son pardos. Cuando es de noche todos nos parecemos, no podemos ver bien y no podemos distinguir las cosas.

El león cree quetodos son de su condición. La persona que piensa o actúa mal cree que todos hacen lo mismo que ella.

Hijo de tigre "pintito". Así se dice de quien, siendo hijo de al guien que tiene excel entes cualidades o es importante y destacado, resulta digno hijo de su padre.

Más vale pájaro en mano, que un ciento volando. Es mejor gozar lo que se tiene, que desear lo que no se puede tener.

Muerto el perro, se acabó la rabia. Se dice que, al morir la causa u origen de un mal, éste por fin desparece.

Para decir mentiras y comer pescado, hay que tener cuidado. El descuido pone en evidencia al mentiroso y puede ahogar a quien coma una espina de pescado.

Perro queladra, no muerde. Hay personas que amenazan mucho y con eso tratan deamedrentar a otros, aunque en real idad nunca se atrevan a llevar a cabo sus amenazas. Y nunca hagan nada en contra de nadie.

Según el sapo es la pedrada. Las personas que dan algún tipo de servicio saben que se puede cobrar más a quien más tiene y así lo expresan.

Pobres animalitos, ¿que culpa tienen de que los hombres les asignemos nuestras cual idades y defectos? 
Dichos de referencia a partes del cuerpo

A palabras necias, oídos sordos. Si lo que al guien dice es una necedad, no hay que escucharlo.

Cada cabeza es un mundo. Ninguna experiencia de vida es igual para los demás.

Caras vemos, corazones no sabemos. Las personas no son lo que aparentan ser.

Dos cabezas piensan más. La consideración de cualquier asunto es más completa y objetiva cuando hay más participantes o colaboradores que cuando lo trata una sola persona.

El interés tiene pies. Consideramos que "lo que se quiere, se puede" y debemos ponernos en acción para conseguirlo.

En boca cerrada no entran moscas. Es mejor estar callado (mantener la boca cerrada) que que decir tonterías o al go que pueda ser molesto para otro.

Mientes, con todos los dientes. Frase humorística a base de la rima entre "dientes" $y$ "mientes" para enfatizar el reclamo por la mentira que al guien nos dice.

Nadie escarmenta en cabeza ajena. Es necesario vivir y aprender de las experiencias de la propia vida, pues no es lo mismo que aprender de los demás.

Ojos que no ven, corazón que no siente. Así piensa el que prefiere no darse cuenta de los problemas para no tener que irritarse o sufrir por su causa.

O todos coludos, o todos rabones. Así se expresa quien reclama una igual dad de derechos.

La referencia más fácil e inmediata es la de nuestro propio cuerpo.

Dichos con alusiones religiosas o tomadas de La Biblia

Al que madruga, Dios lo ayuda. El quees persistente y trabajador obtiene siempre buenos resultados. Quien se levanta temprano tiene tiempo para hacer muchas otras cosas más, antes que otros y con ventaja sobre ell os.

A quien no habla, Dios no lo oye. Para obtener al go es necesario abrir la boca y solicitarlo, pues con silencio no se consigue. 
Dios los cría y ellos se juntan. Se dice de los jóvenes que se enamoran. Se considera que nacen, y crecen por su lado, para venir a encontrarse en al gún momento de la vida y unirse por afinidad.

La ley de Herodes: o chingas o te jodes. (perjudicas o sal drás perjudicado). Esta sentencia indica que a veces es necesario hacer daño a otros con tal de no sufrir uno mismo los problemas.

Ni tanto que queme al santo, ni tanto que no lo al umbre. Las cosas siempre deben hacerse de forma equilibrada. Alude a la vela encendida que se ofrece ante la imagen de un santo en la iglesia, la cual si está muy cerca puede incendiarla y muy lejos no le da luz suficiente para que se vea.

Ponerse con Sansón a las patadas. Caer en disputa con al guien más fuerte y poderoso.

Dichos propios del ámbito campesino

A caballo dado, no se le ve colmillo. Sentencia que consigna: "Si te regalan algo, no le busques defectos y agradécelo".

Ahí es donde la puerca torció el rabo. Se dice cuando las cosas se complican en cierto punto o momento.

Al nopal nomás lo ven cuando tiene tunas. Es común visitar a los amigos o conoci dos cuando necesitamos un favor de ellos.

Al ojo del amo, engorda el caballo. Las cosas salen mejor cuando atendemos nuestros asuntos. También se dice: "El que tenga tienda, que la atienda".

Cada oveja con su pareja. Así se indica que, para todo individuo, siempre hay al guien que lo pueda comprender (por ser igual o semejante).

El miedo no anda en burro. Es decir, nunca reacciona con lentitud, sino al contrario.

El que a buen árbol se arrima, buena sombra lecobija. Siempre es bueno estar bajo la protección y apoyo de al guien con mayores recursos y posibilidades que uno.

El que con lobos anda, a aullar se enseña. Se dice del que, andando con amigos que no le convienen, se vuelve como ellos. 
El que es buen gallo, dondequiera canta. Con esto afirmamos que las cualidades personal es o profesionales pueden demostrarse donde sea.

Mientras menos burros, más olotes. A la hora de repartir, cuanto menor es el número de beneficiados, mayor es la cantidad que nos corresponde.

Sólo el que carga el costal sabe lo que lleva dentro. Unicamente aquel que padece de un mal sabe lo que está sufriendo (y lo que significa soportarlo).

Tanto peca el que mata la vaca, como el que le detiene la pata. Tan culpable es quien comete una falta, como quien le ayuda o lo solapa.

Ve burro y se le ofrece viaje. Esto se expresa al que, viendo que al guien acaba un trabajo, lo llama para asignarle otra tarea, es decir lo aprovecha.

Ver la paja en el ojo ajeno. Ver los defectos de los demás y no ser capaces de ver los propios.

Yerba mala, nunca muere. Se cree que los malvivientes y personas indeseables para la sociedad viven más que la gente honesta y decente. También es una expresión usada por las personas que, luego de una convalescencia, reafirman que todavía no les toca morir.

Contamos con todo ti po de enseñanzas encerradas en los dichos. Esto es importante porque constituyen una rica fuente de referencia sobre nosotros mismos, un espejo de lo que somos y de lo que podriamos cambiar, aunque tal vez ahora sólo reflejan una realidad cada vez más lejana, pues aparentemente muchos han sido olvidados o estan siendo arrinconados (mucha gente ya no los conoce o bien confunde o mal entiende su significado, su uso y su contenido), a pesar de consituir experiencias de vida pal pables.

\section{EL MUNDO INEXISTENTE}

¿Qué pasaría si por usar un refrán popular al guien que pecara de culto enunciara un popular dicho con pal abras más "aladas" como decian los clásicos? Pues produciría un híbrido como el siguiente: "Tiene mayor valor un plumífero volador, en la fosa metacarpiana, que segunda 
potencia de diez pululando por el espacio" (en lugar de: "Más vale pájaro en mano que ciento volando"). Claro que estamos en el plano de las suposiciones, de por sí vagas, y habrá quien piense que este ejercicio es más bien ocioso y no lleva a ninguna parte. Pero sucede que ése es precisamente el objetivo: Ios dichos surgieron en un momento de libertad, en un momento de descuido de quienes quisieron contener la experiencia vital, la imaginación y la creatividad lingüística de usuarios libres y soberanos, aunque en sus inicios sólo lo fueran en su lenguaje.

$\mathrm{Si}$ alguien enunciara un dicho de la forma culta al terada que hemos señal ado, podríamos ver que estaría fingiendo y carecería de una identidad precisa. Una enunciacion tal, esta expresión así falseada, se perdería en la ambigüedad en cuanto a la posible cara del responsible de su enunciación: sería muy difícil saber si lo de plumífero volador lo estaría identificando como biólogo o como veterinario, frente a las palabras "fosa" $y$ "metacarpiana", que lo harían ver como médico, sin descartar que también podría ser identificado como matemático o físico, por aquello de la "segunda potencia de diez". De todos modos resultaría poco atractivo atender a su mensaje, pues al perder el poder de la evocación tampoco sería escuchado. Esto prueba, por un lado, la importancia del contexto, del momento y de la persona que profiere un refrán, y, por el otro —quizá más importante aún-demuestra la natural eza del mismo.

Siempre es triste pensar que nuestros refranes pudieran estar convirtiéndose en una más de las actual es especies en extinción, pero más lamentable resulta pensar que es tal vez la imaginación y creatividad queles dieron vida lo que se está perdiendo. Al volver a reflexionar sobre el concepto de lo "culto" vemos que también se refiere específicamente a lo "especializado" y "enterado", perteneciente a muchos otros mundos que nos son ajenos, presentados ante nuestros ojos por referencias de terceros, quienes también los recibieron de al guien más y se los impusieron. Lamentable es presenciar la pérdida de los refranes, pero más lo es la pérdida del fenómeno social que representan. Quien expresara el anteriormente referido refrán modificado con pal abras cultas habríatenido 
que recurrir a una elaboración basada en fuentes diversas, en diversos campos del conocimiento humano para poder hacerlo, dejando fuerasu propia experienciay personalidad.

\section{UN EJ ERCICIO FILOSÓFICO}

Si al guien seatreviera a violentar el orden conseguido por las expresiones populares, tan bien logradas, tan sintéticas, precisas y valiosas, sencillamente tendría que enfrentarse a la total incomprensión, aun de aquellos a quienes pudiera sonar familiar la nueva selección de pal abras real izada. Por ende, su mensaje perdería, además de la intersubjetividad que supone toda comunicacion, arruinaría -aludiendo a Austin- la fuerza ilocutiva que parece seleccionada desde el interior del refrán mismo.

Qué imagen nos ofrecería quien profiriera estos refranes de la siguiente manera:

1. "Crustáceo que pierde el estado de vigilia es arrastrado por el ímpetu marino" (Camarón que se duerme se lo lleva la corriente).

2. "Relátame con quien deambulas y evaluaré con ello tu ser" (Dime con quién andas y te diré quién eres").

3. A perturbación ciclónica en el ambiente, rostro jocundo ( $A$ mal tiempo, buena cara).

4. $\mathrm{H}_{2} \mathrm{O}$ que no has de ingurgitar, permítele discurra por su cauce (Agua que no has de beber, déjala correr).

5. Ocúpate de alimentar y cuidar de las aves córvidas y te extirparán los gl obos oftálmicos (Cría cuervos y te sacarán los ojos).

Si esto sucediera, cada experto expresaría sus refranes con una mayor o menor precisión al depender desu lenguaje profesional, filosófico o científico y al final sabría que el esfuerzo no val ió la pena, por reflejar -el lenguaje- mundos distintos a los que refieren y ponen ante nuestros ojos los refranes.

Fueron al gunos anónimos caballerangos quienes primero concluyeron que "Al ojo del amo engorda el caballo", 
porque la lengua no es construida por un sólo individuo, si bien al gún otro grupo, como el de los médicos, pudieran haber dicho "Al globo oftálmico del poseedor, el equino tórnase obeso". Y, en ese mismo sentido:

1. Quien haya salido alguna vez de día de campo sabe que "Al que a buen árbol se arrima, buena sombra le cobija", si bien este se convirtió en el consejo más sabio dentro de la estructura de relaciones social es que llevan a los individuos al éxito o al fracaso dependiendo de la calidad e sus relaciones sociales. Como sea, qué bueno que nadie pudo decir antes: "Quien a ubérrima conífera se adosa, óptima umbría su ser entolda".

2. El ranchero sabe que "A caballo dado no se le ve colmillo", lo que un veterinario hubiera podido expresar como: "Al equino que es objeto de un obsequio, no se le anal izan sus piezas dentales".

3. Cualquier individuo convencido de que "Ojos que no ven, corazón que no siente", estará ganádole al médico la oportunidad de que expresar: “La ausencia absoluta de percepción visual, torna insensible al órgano cardiaco", que sería más propio de una clase de anatomía que de una advertencia o enseñanza.

4. El individuo satisfecho dirá "Barriga llena corazón contento", al udiendo a un bienestar que sólo el siente, independientementedelacausa quelo haya originado, y dejará atrás a una frase de tipo médico como: "Una cavidad gástrica satisfecha, tiene un efecto eufórico directo en nuestra víscera cardiaca". Fue la vida cotidiana, el entorno y el ojo agudo de la gente, la que llevo a la creación de los dichos, no la asi stencia a una universi dad ni la pertenencia a un grupo selecto. 


\section{CONCLUSIÓN}

Los dichos son el mejor recurso para poner los pies en la tierra y contrarrestar el efecto de las cosas ratifícales y las "al adas y cultas" pal abras, qué feli cidad que haya contrastes y un lugar para cada tipo de lenguaje, no porque se lo endil guemos, sino porque la propia natural eza y sociedad se lo han otorgado. Qué bien contar con recursos para que las enseñanzas vitales puedan ser claras, evocadoras, relajadas, sugerentes y accesibles para todos. Qué al egría que intervengan siempre los justos medios, que permiten el descanso y la relajación mental. Qué suerte poder descansar el al ma al dejar queésta se balancee suavemente dentro de la sencillez del enunciado refranero, con sus enromes y bellas enseñanzas condensadas, poniendo las cosas frente a nuestros ojos de la manera en que lo hace.

Habrá quien luego de haber leído hasta este punto aún siga pensando que no lleva hacia ningún destino o incluso piense con recel o que aquí hay un felino en cautiverio. Pero no hay tal , ésta es sól o una manera más de reflexionar sobre las diferencias entre los lenguajes y las causas que las han originado, más que establecerlas o anal izarlas, mediante un discurso técnico. Y es quetratándose de unidades fraseológicas, de expresiones cristalizadas o de discurso repetido como han Ilamado los expertos a los refranes, éstas no dejan de ser ejemplo de reflexiones personal es, heredadas y mágicas, que hi pnotizan a quien las escucha haciéndolo entender sin necesidad de quelas piense ni I as reflexione en su contenido. Es dellamar la atención que su sentido se da siempre por sentado.

I maginen ustedes, como un últmo ejercicio hipotético, lo que pasaría si los pintores violentaran su manera de hablar y lo hicieran como lo hacen los críticos de arte, o si los sargentos hablaran como diplomáticos: cómo se saludarían, de qué modo hablarían, si segurían siendo ellos mismos, si serían auténticos. 
Polo, José. Lenguaje, gente, humor / materiales para una antología semántica

española . Madrid,

Ed. Paraninfo, 1972, pp. 96-97.
SI LOS PINTORES HABLARAN COMO LOS CRÍTICOS DE ARTE ${ }^{1}$

Por Álvaro de Laiglesia

— ¡H ola, conjugador de cálidos matices! ¿Qué es de tu plasma vital?

- Pues ya ves, hipersensi ble esteta y amigo mío: aquí me tienes, armonizando volúmenes.

- ¿Sigues expresando con tu pincelada sutil la emanación translúcida del objeto inerte?

- Si, pero poco. Ahora practico la yuxtaposición de tetraedros para sincopar las perspectivas.

- Haces bien. Yoyuxtapongo muy poco, por lo cual se me evaden los pál pitos emocionales.

- Pero obtendrás a cambio unos contrastes lumínicos de abolengo velazqueño.

- Eso sí, y gracias a ello permanezco incólume frente a la catarata rapsodista de los bermellones...

- Pues es una ventaja, hijo: yo sufro una introspección colorativa de las contexturas etéreas, que me deja el espíritu insomne.

- ¿Estuviste en la exposición de Chufo Colín?

— ¡Uh!, Ya sabes que hurto mi asistencia a los gárulos que se exceden en la estridencia de lastangentes.

- Pues me han dicho que logra unas masas egocéntricas que infunden transparencias a los perfiles que plasma.

- ¡Vamos, anda, plasmao! Chufo no es más que un clasicista esquemático de resabios pigmentados.

- Eso creo yo; ha subido con demasiada rapidez los pel daños de la escal a cromática, y al Ilegar arriba se cayó de narices.

- Jamás perteneció a ninguna escuela; ni a la futurista, ni a la chafarrionista, ni a la engañifista...

- Pues es raro, porque su padre pertenecia a la escuela estraperlista.

- ¿Vas a exponer esta temporada al guna sublimación de tu exquisito sentido plástico?

- Quizás. He terminado al gunas telas de vigoroso contenido, pero no me satisface la dispersión de sus clarosocuros, que redundan en detrimento de su intensidad abismal. 
- Pues hijo: te ahogas en un vaso de agua. Recurre a una interpretación simplista de criterio y así obtendrás un latido de resonancias cósmicas en el vértice de su singularización estética.

- ¡Es verdad, muchacho! ¿Cómo no se me había ocurrido una cosa tan sencilla?

- Esqueno hay nada como hablar claro para entenderse.

- Pues colorin colorado, esteta.

- Colorin colorado, plástico.

SI LOSSARGENTOS HABLASEN COMO LOS DIPLOMATICOS ${ }^{2}$

Por Álvaro de Laiglesia

Sargento: Me agradaría mucho que tuviera usted la bondad de dar media vuelta a la derecha.

Recluta: ¿Con que objeto?

Sargento: Si he de ser sincero, es un capricho quetengo desdela infancia. Se trata de un entretenido ejercicio, muy apto para reclutasjóvenes.

Recluta: Siendo así, tendré sumo gusto en complacerle.

Sargento: Muchisimas gracias. ¿Será abusar de su gentileza rogarle que repitiese la media vuelta, pero esta vez hacia la izquierda?

Recluta: Temo que quedaré en la misma posición que al principio.

Sargento: ¡Es verdad, que tonto soy! Pero observo en su rostro síntomas de fatiga. ¿Le apetecería ponerse en su lugar de descanso?

Recluta: Es usted muy amable, pero no quisiera molestar...

Sargento: Vamos, sin cumplidos. Ha tomado usted posesión de su cuartel.

Recluta: Gracias. Me pondré en mi lugar de descanso, pero sólo un instante.

Sargento: Me daría usted un gran alegrón si presentase armas.

Recluta: ¡No fal taría más! Ya está.

Recluta: ¿Con que objeto? 
Sargento: ¡Que alocada juventud! Su postura, si me permite una sugestión, no es del todo correcta: es conveniente que suj ete la culata del fusil con el pulgar y el índice de la mano derecha.Se da usted muy poquita maña, ¡eh!

Recluta: Le prometo que porcuraré perfeccionarme en mis ratos libres.

Sargento: ¡Ajaja! Veamos ahora si es usted capaz de colocarse el fusil sobre el hombro. Suponiendo, claro está, que ello no le cause ningún trastorno.

Recluta: Reconozco que mis movimientos son al go torpes.

Sargento: ¡Oh, por Dios, no se preocupe!; para eso estamos aquí a su disposición. ¿Qué le parecería marchar un poco de frente?

Recluta: Si no hay que ir muy lejos, quizá...

Sargento: No me propongo cansarle con una caminata, por Dios; sólo unos cuantos pasos, y en seguida le di ré que puede usted hacer al to.

Recluta: Hablándole con toda franqueza, preferiría no tener que andar.

Sargento: Es usted muy libre. ¿Acaso le aprieta una bota?

Recluta: No es eso, exactamente; tengo una dureza en el talón que me escuece.

Sargento: Pues le recomiendo este remedio: cuando se descalce esta noche, frótese la zona doIorida con suavidad, y diga: "Sana, sana, piecito de rana, si no sanas hoy, sanaras mañana".

Recluta: Así lo haré...

Sargento: Bueno pues, si lo desea, puede romper filas cuando le plazca.

Recluta: Lo haré inmediatamente, pues bastante tiempo le he robado.

Sargento: ¡Nada de eso! Para mí ha sido un placer enseñarle la instrucción.

Recluta: Siempre a sus órdenes, sargento.

Sargento: No hay de que, recluta. 